\title{
Surviving in a Cosexual World: A Cost-Benefit Analysis of Dioecy in Tropical Trees
}

\author{
Marjolein Bruijning, ${ }^{1, \star}$ Marco D. Visser, ${ }^{1,2}$ Helene C. Muller-Landau, ${ }^{2}$ S. Joseph Wright, ${ }^{2}$ \\ Liza S. Comita, ${ }^{2,3}$ Stephen P. Hubbell, ${ }^{2,4}$ Hans de Kroon, ${ }^{1,2}$ and Eelke Jongejans ${ }^{1}$
}

\begin{abstract}
1. Departments of Experimental Plant Ecology and Animal Ecology and Physiology, Institute for Water and Wetland Research, Radboud University, Nijmegen, The Netherlands; 2. Smithsonian Tropical Research Institute, Box 0843-03092, Balboa, Ancón, Panama; 3. School of Forestry and Environmental Studies, Yale University, New Haven, Connecticut 06511; 4. Department of Ecology and Evolutionary Biology, University of California, Los Angeles, California 90024
\end{abstract}

Submitted February 9, 2016; Accepted October 11, 2016; Electronically published January 10, 2017

Online enhancements: appendix, supplement.

\begin{abstract}
Dioecy has a demographic disadvantage compared with hermaphroditism: only about half of reproductive adults produce seeds. Dioecious species must therefore have fitness advantages to compensate for this cost through increased survival, growth, and/or reproduction. We used a full life cycle approach to quantify the demographic costs and benefits associated with dioecy while controlling for demographic differences between dioecious and hermaphroditic species related to other functional traits. The advantage of this novel approach is that we can focus on the effect of breeding system across a diverse tree community. We built a composite integral projection model for hermaphroditic and dioecious tree populations from Barro Colorado Island, Panama, using long-term demographic and newly collected reproductive data. Integration of all costs and benefits showed that compensation was realized through increased seed production, resulting in no net costs of dioecy. Compensation was also facilitated by the low contribution of reproduction to population growth. Estimated positive effects of dioecy on tree growth and survival were small and insignificant for population growth rates. Our model revealed that, for long-lived organisms, the cost of having males is smaller than generally expected. Hence, little compensation is required for dioecious species to maintain population growth rates similar to those of hermaphroditic species.
\end{abstract}

Keywords: breeding system, elasticity, functional traits, integral projection model, life cycle analysis, vital rates.

\section{Introduction}

Although separate sexes are very common in mobile animals, dioecy is quite rare in plants. Only $6 \%-10 \%$ of angio-

\section{* Corresponding author; e-mail: m.bruijning@science.ru.nl.}

ORCIDs: Visser, http://orcid.org/0000-0003-1200-0852; Muller-Landau, http://orcid.org/0000-0002-3526-9021; Wright, http://orcid.org/0000-0003-4260 -5676; Comita, http://orcid.org/0000-0002-9169-1331; Hubbell, http://orcid.org 10000-0003-2797-3411; de Kroon, http://orcid.org/0000-0001-6151-3561; Jongejans, http://orcid.org/0000-0003-1148-7419.

Am. Nat. 2017. Vol. 189, pp. 297-314. (C) 2017 by The University of Chicago. 0003-0147/2017/18903-56784\$15.00. All rights reserved.

DOI: $10.1086 / 690137$ sperms are dioecious (Renner and Ricklefs 1995). This rarity may reflect demographic costs associated with dioecy (Bawa 1980): when a large proportion of the population are males, population growth is reduced — all else being equal — relative to when all individuals produce seeds. Having fewer seedproducing individuals is thus expected to constitute a substantial fitness disadvantage (Queenborough et al. 2007; Vamosi et al. 2007, 2008). Nonetheless, dioecy has evolved independently at least 100 times (Charlesworth 2002; Barrett 2010) and is represented among almost half of angiosperm families (Renner and Ricklefs 1995). It follows that in order to coexist with hermaphroditic species, dioecious species must have compensatory fitness advantages (Bawa 1980; Heilbuth et al. 2001). Although increased genetic variation and decreased inbreeding depression may partly explain the benefits, it is difficult to explain dioecy simply as a mechanism favoring outbreeding given that most hermaphroditic species also have efficient outbreeding mechanisms (Bawa 1974; Renner and Ricklefs 1995; Freeman et al. 1997). Identification of the benefits of dioecy and quantification of how dioecious species compensate for the costs is therefore an intriguing and long-standing challenge in ecology (e.g., Darwin 1877; Opler and Bawa 1978; Armstrong and Irvine 1989; Renner and Ricklefs 1995; Freeman et al. 1997; Vamosi 2008; Queenborough et al. 2009).

Different compensating mechanisms have been proposed. Dioecious species may be able to invest more in reproduction, growth, and/or survival because they produce only staminate or pistillate flowers (Bawa 1980; Queenborough et al. 2007, 2009; Vamosi et al. 2008). Reproductive investment focused on one flower type may enable increased seed production, an earlier age of reproduction, more frequent reproduction, and/or production of better-quality seeds, leading to higher seedling establishment or survival (Heilbuth et al. 2001; Queenborough et al. 2009). However, the two studies that have compared these vital rates between dioecious and nondioecious 
species have found little evidence that females in dioecious species benefit from the absence of costs associated with the production of staminate flowers (Vamosi et al. 2008; Queenborough et al. 2009).

A challenge in making such comparisons between dioecious and nondioecious species is that species invariably differ in other traits as well- traits that may also influence interspecific variation in vital rates. For example, seed production is closely related to seed mass (Moles et al. 2004; Muller-Landau et al. 2008), and growth and mortality rates vary with wood density and adult stature (Muller-Landau 2004; Kraft et al. 2010). Functional traits like seed mass, wood density, and maximum size vary widely among tropical tree species and explain significant variation in vital rates (Poorter et al. 2008; Wright et al. 2010; Visser et al. $2016 b$ ). Proper estimation of demographic effects of breeding systems in particular thus requires controlling for the effects of interspecific variation in these other traits.

A complete picture of the benefits and costs of dioecy also requires integrating effects across the entire life cycle, something no previous study has done. A life cycle analysis is critical for two reasons. First, different life stages contribute differently to population growth. For this reason, the size of effects on individual vital rates provides limited insight into effects on population growth (de Kroon et al. 1986; Ehrlén 2003). Second, breeding system affects multiple fitness components; benefits in one life stage may be offset by costs in other life stages (Visser et al. 2016b). Simple comparisons of single vital rates between breeding systems, without considering correlations and trade-offs, cannot demonstrate differences in population growth rates. Hence, we do not know how dioecious plant species survive in a cosexual world.

Here we perform an analysis that encompasses the entire life cycle to evaluate the fitness consequences of dioecy versus hermaphroditism for trees from the tropical moist forests of Barro Colorado Island (BCI), Panama. We take advantage of the relatively high occurrence of dioecy in tropical forests $(21 \%$ of species on BCI [Croat 1978] and 16\%-28\% elsewhere [Opler and Bawa 1978; Zapata and Arroyo 1978; Bawa 1980]) and the demographic data available for many BCI tree species (Hubbell and Foster 1983, 1992; Wright et al. 2005b; Muller-Landau et al. 2008; Comita et al. 2010) and add individual data on fruiting or flowering probabilities for 23 hermaphroditic and 17 dioecious species and on sex for eight dioecious species. We model vital rates as a function of individual size and four species traits: breeding system, seed mass, wood density, and adult stature (Poorter et al. 2008; Wright et al. 2010; Visser et al. 2016b). We use the resulting vital rate functions to construct a "composite" integral projection model (IPM) as a function of trait values (including breeding system) rather than separate IPMs for each species. Our composite approach quantifies the effects of breeding system across a tree community while controlling for interspecific demographic variation related to other functional traits. We evaluate six hypotheses concerning possible benefits associated with dioecy, all premised on reallocation of resources consumed by male and female function in hermaphrodites (Heilbuth et al. 2001; Barot and Gignoux 2004; Vamosi et al. 2008; Queenborough et al. 2009). Dioecious females might allocate more resources to seed production than do hermaphrodites, leading to (1) increased seed production and/or higher quality seeds characterized by (2) greater seedling establishment, (3) higher seedling survival, and/or (4) higher seedling growth rates. Dioecious males and females might both allocate more resources to their own maintenance than do hermaphrodites, leading to greater (5) adult survival and/or (6) adult growth rates. We use vital rate functions to evaluate each of these six hypotheses individually. We then use the composite to evaluate how each vital rate difference individually and all vital rate differences simultaneously affect intrinsic population growth rates.

\section{Methods \\ Model Framework}

Species vary not only in breeding system (the focus of this study) but also in other traits that influence population dynamics, and variation due to other traits may dilute or mask the demographic effects of breeding system. For instance, plant breeding system is hypothesized to affect crop size (Queenborough et al. 2009), but this effect will be modest compared with the much larger effect of seed mass, a major determinant of crop size (Moles and Westoby 2006; Muller-Landau et al. 2008). When comparing a random dioecious species with a random hermaphroditic species, the effect of the difference in breeding system cannot be distinguished from the effects of differences in other traits. We therefore used a community approach with as many species as possible while including important species traits in the analyses to isolate the role played by breeding system. Moreover, plant traits have opposing effects across the life cycle, and robust ecological inference therefore requires integration of the net effect through population models (Visser et al. $2016 b$ ). To do so, we built a composite IPM to integrate the effects of breeding system across the life cycle while simultaneously controlling for the effects of three other key traits. This enabled a clear focus on one particular aspect of lifehistory strategies: breeding system.

We begin by explaining the structure of the composite IPM and vital rate functions. The vital rate functions incorporate three functional traits (seed mass, wood density, and adult stature; see, e.g., Visser et al. 2016a) and breeding system. Second, we explain our statistical approach for 
fitting the vital rates through model averaging and provide an overview of the study site and data used. Finally, we explain the cost-benefit analysis of dioecy. Here, we project the intrinsic growth rate, a measure of population fitness (Charlesworth 1980; Caswell 2001; Metcalf and Pavard 2007), of a hermaphrodite species at fixed trait values. We then systematically exchange hermaphroditic vital rate functions for dioecious vital rate functions. The resulting differences in intrinsic growth rate measure the population-level cost or benefit of dioecy while controlling for the effects of other traits. We then repeated this for different trait values to explore the possibility that dioecy might be favored over some subset of seed mass, wood density, or adult stature values.

\section{Composite IPM}

IPMs describe population dynamics in discrete time, with continuous functions that relate vital rates (survival, growth, reproduction) to continuous state variables (Easterling et al. 2000; Ellner and Rees 2006), here size and traits. We constructed a two-stage composite IPM across a wide range of species in which all vital rates were functions of both individual size and species-specific trait values $\mathbf{z}$. Here, $\mathbf{z}$ is an array that contains trait values for seed mass (SM), wood density (WD), adult stature $\left(D_{\max }\right)$, breeding system ( $B$; DIO or HERMA), and female proportion (set at 1 for hermaphrodites, where all individuals produce seeds). We chose a single-sex model rather than separately modeling males and females of dioecious species, as no data on mating and pollination rates for the community exist. These processes could play a different role in dioecious than hermaphroditic species. However, by directly looking at the seed production offemales, the net outcome of these processes can be examined without the need for explicitly modeling these unobserved rates.

The two-stage composite IPM consisted of a seedling and tree stage, with height $(\mathrm{mm})$ and diameter breast height $(\mathrm{DBH} ; \mathrm{mm})$ as continuous state variables, respectively. Seedling height ranged up to a species-specific $C_{\text {seedling, }}$ and tree $\mathrm{DBH}$ ranged between $10 \mathrm{~mm}$ and a species-specific $C_{\text {tree. }}$ $C_{\text {seedling }}$ is defined as the estimated height at which stems reach a DBH of $10 \mathrm{~mm}$, and $C_{\text {tree }}$ is defined as the maximum DBH $\left(D_{\max }\right)$. The time step was annual (year $t$ to year $t+1$ ).

The two-stage IPM consisted of four kernels that describe all size-dependent transitions within and between the two stages (fig. 1). All four kernels included multiple underlying vital rate functions, as explained below (eqq. [3]-[6]). The IPM can be written using two equations that are the addition of two kernels that describe transitions between sizes and stages. The first describes how the number of seedlings of various sizes in year $t+1$ is a function of contributions

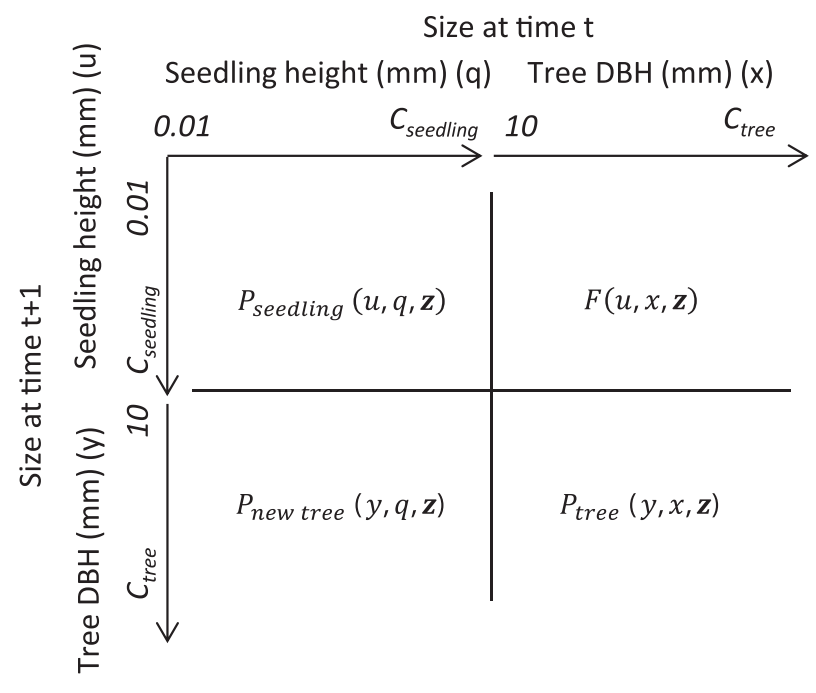

Figure 1: Overview of the composite integral projection model (IPM), which includes four kernels ( $F=$ reproduction, $P=$ survival and growth) that together represent all transitions of and reproductive contributions by individuals of size $q$ (seedling height in millimeters) and size $x$ (tree diameter in millimeters) at time $t$ to the number of individuals of size $u$ and $y$ at time $t+1$. All kernels are functions of trait values $\mathbf{z}$ (including seed mass, wood density, maximum diameter breast height $[\mathrm{DBH}]$, breeding system, and, if dioecious, the proportion female).

by seedlings (through survival) and trees (through reproduction) of the previous year:

$$
S_{t+1}(u, \mathbf{z})=\int_{0.01}^{C_{\text {seding }}} P_{\text {seedling }}(u, q, \mathbf{z}) S_{t}(q, \mathbf{z}) \mathrm{d} q+\int_{10}^{C_{\text {rues }}} F(u, x, \mathbf{z}) T_{t}(x, \mathbf{z}) \mathrm{d} x .
$$

Here $P_{\text {seedling }}(u, q, \mathbf{z})$ describes the survival and growth of seedlings with size $q$ to size $u, S_{t}(q, \mathbf{z})$ describes the size distribution of seedlings in year $t$, and $F(u, x, \mathbf{z})$ describes the arrival of new seedlings with size $u$ based on the size distribution of trees in year $t\left(T_{t}(x, \mathbf{z})\right.$; eqq. [3], [4]).

The second equation describes the contributions to the number of trees of various sizes at time $t+1$ :

$$
T_{t+1}(y, \mathbf{z})=\int_{10}^{C_{\text {nexe }}} P_{\text {tree }}(y, x, \mathbf{z}) T_{t}(x, \mathbf{z}) \mathrm{d} x+\int_{0.01}^{C_{\text {sedang }}} P_{\text {new tree }}(y, q, \mathbf{z}) S_{t}(q, \mathbf{z}) \mathrm{d} q .
$$

Here $P_{\text {tree }}(y, x, \mathbf{z})$ describes the growth and survival of trees with size $x$ to size $y$, and $P_{\text {new tree }}(y, q, \mathbf{z})$ describes the transition from seedlings to trees (eqq. [5], [6]).

To enable computation of the asymptotic population growth rate $(\lambda)$, we discretized the composite IPM into a matrix of $800 \times 800$ size classes $(200$ seedling height and 600 tree $\mathrm{DBH}$ classes). $\lambda$ is then calculated as the dominant eigenvalue of the matrix. Our size class resolution resulted in robust esti- 
mates of population growth rates $(\lambda)$ with any increase in dimensions having a negligible effect on $\lambda(<0.00001)$. The phenomenon of "eviction" — when individuals near the size boundaries are predicted to grow outside the range (Williams et al. 2012) — was avoided by adding the probabilities of growing smaller or larger than the boundaries to the outer size classes. Size class widths in height and diameter are species specific, depending on $C_{\text {seedling }}$ and $C_{\text {tree }}$, respectively, and are calculated as $C_{\text {seedling }} / 200$ for seedlings and $C_{\text {tree }} / 600$ for trees. At average trait values, this results in widths of $12 \mathrm{~mm}$ for height and $0.25 \mathrm{~mm}$ for $\mathrm{DBH}$.

\section{Underlying Vital Rate Functions}

The four kernels that form the composite IPM (eqq. [1], [2]) are constructed with multiple trait-dependent vital rate functions. The reproduction kernel gives the expected production of seedlings of sizes $u$ at time $t+1$ by a tree of size $x$ at time $t$ :

$$
F(u, x, \mathbf{z})=p_{\text {female }}(\mathbf{z}) \cdot p_{\text {repr }}(x, \mathbf{z}) \cdot f_{\text {seeds }}(x, \mathbf{z}) \cdot p_{\text {establishment }}(\mathbf{z}) \cdot f_{\text {dist }}(u, \mathbf{z}),
$$

where $p_{\text {female }}$ is the probability of being female (i.e., proportion females), $p_{\text {repr }}$ is the probability of being reproductive, $f_{\text {seeds }}$ is the expected seed production of an individual reproductive female tree, $p_{\text {establishment }}$ is the probability of seedling establishment, and $f_{\text {dist }}$ is the offspring size distribution, giving the probability of a new recruit having initial height $u$.

The seedling kernel represents survival and growth of seedlings with height $q$ at time $t$ that remain seedlings with height $u$ at time $t+1$ :

$$
P_{\text {seedling }}(u, q, \mathbf{z})=p_{\text {sdl survival }}(q, \mathbf{z}) \cdot p_{\text {sdl growth }}(u, q, \mathbf{z}) .
$$

Note that the $P_{\text {seedling }}$ kernel includes new sizes only up to the height $C_{\text {seedling. }}$ Surviving seedlings that grow larger than $C_{\text {seedling }}$ are represented in the $P_{\text {new tree }}$ kernel, which represents transitions of seedlings with height $q$ at time $t$ to trees with diameter $y$ at time $t+1$. This $P_{\text {new tree }}$ kernel is a function of seedling survival and growth and of the function for converting tree $\mathrm{DBH}$ to seedling heights $(u=h(y))$. This conversion is needed to properly integrate over the $\mathrm{DBH}$ classes and thus translate the output of the seedling growth function from height to $\mathrm{DBH}$ :

$P_{\text {new tree }}(y, x, \mathbf{z})=p_{\text {sdl survival }}(x, \mathbf{z}) \cdot p_{\text {sdl growth }}(h(y), q, \mathbf{z}) \cdot(\mathrm{d} h / \mathrm{d} y)$,

where $h(y)$ is the inverse of the function $g(u)$ for converting seedling heights to tree diameters (table 1 ).

Finally, the tree kernel represents transitions of trees with a DBH of $x$ at time $t$ to a DBH of $y$ at time $t+1$ and is a function of tree survival $\left(p_{\text {tree survival }}\right)$ and tree growth $\left(p_{\text {tree growth }}\right)$ :

$$
P_{\text {tree }}(y, x, \mathbf{z})=p_{\text {tree survival }}(x, \mathbf{z}) \cdot p_{\text {tree growth }}(y, x, \mathbf{z}) .
$$

\section{Functional Traits}

The composite IPM is a function of three key functional traits (Visser et al. 2016b) — seed mass, wood density, and adult stature - in addition to breeding system and female proportion. Seed mass (SM; $\mathrm{g}$ ) is the dry mass of the embryo and endosperm only. Wood density $\left(\mathrm{WD} ; \mathrm{g} / \mathrm{cm}^{3}\right)$ is ovendried mass divided by fresh volume (technically, woodspecific gravity). We averaged values for mass dried at $60^{\circ}$ and at $100^{\circ} \mathrm{C}$. Maximum diameter $\left(D_{\max } ; \mathrm{mm}\right)$, henceforth referred to as maximum size, is a proxy for adult stature that correlates well with measured maximum heights $(r=0.93$, on a log-log scale). Preliminary analyses also included specific leaf area, but it explained minimal variation in vital rates and was therefore dropped (Visser et al. 2016b). Wright et al. (2010) describe detailed methods and provide values for SM, WD, maximum height, and specific leaf area. To facilitate comparison among effect sizes, we normalized $\mathrm{SM}, \mathrm{WD}$, and $D_{\max }$ (by subtracting the mean and dividing by $1 \mathrm{SD}$ ) using all species in the databases (see below), with SM and $D_{\max } \log$ transformed prior to normalization. Breeding system $(B)$ is hermaphroditic (HERMA) or dioecious (DIO) and is obtained from Croat (1978). We excluded monoecious and polygamous species, which comprised $8 \%$ and $4 \%$ of tree species at BCI, respectively.

We used data for 123 species. For each vital rate we included varying subsets of species depending on data requirements and availability at each life stage (table 1; appendix, available online). This allowed us to maximize power by using all available data at each vital rate and life stage to test for the effect of breeding system while accounting for interspecific variation associated with traits. To ensure that estimated effects of breeding system were not biased by different trait or size distributions between breeding systems, we compared the distributions of $\mathrm{WD}$, $\mathrm{SM}, D_{\max }$, and individual size between breeding systems for each vital rate (suppl. sec. S1; supplement is available online).

\section{Statistical Fitting of Vital Rate Functions}

For each vital rate function, we fit multiple models, one for each possible combination of traits and, where relevant, trait-size interactions, and then applied model averaging over these models (weighted by the Akaike information criterion $[\mathrm{AIC}]$ ) to calculate average parameters (Burnham and Anderson 2002). Model averaging is considered more robust for inference and prediction than simply using the single best model because models with a fit similar to the best model are not ignored (Burnham and Anderson 2002; Whittingham et al. 2006; Bolker et al. 2009). On the condition that model assumptions are met (e.g., no multicollinearity or nonlinearities; Cade 2015), model averaging provides a more robust basis for inference and prediction, reducing bias in 


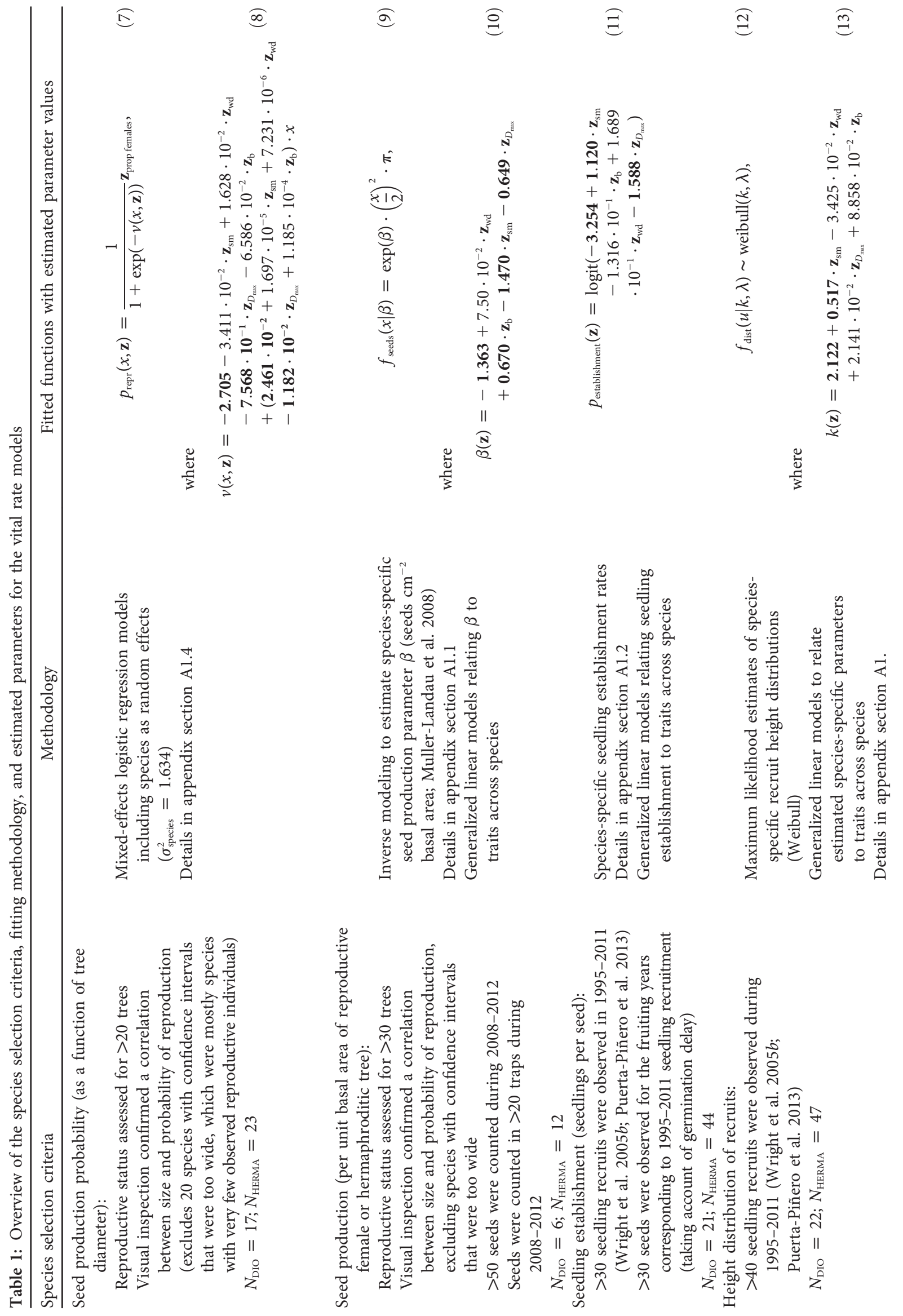

This content downloaded from 131.174.248.154 on July 28, 2017 05:21:42 AM 


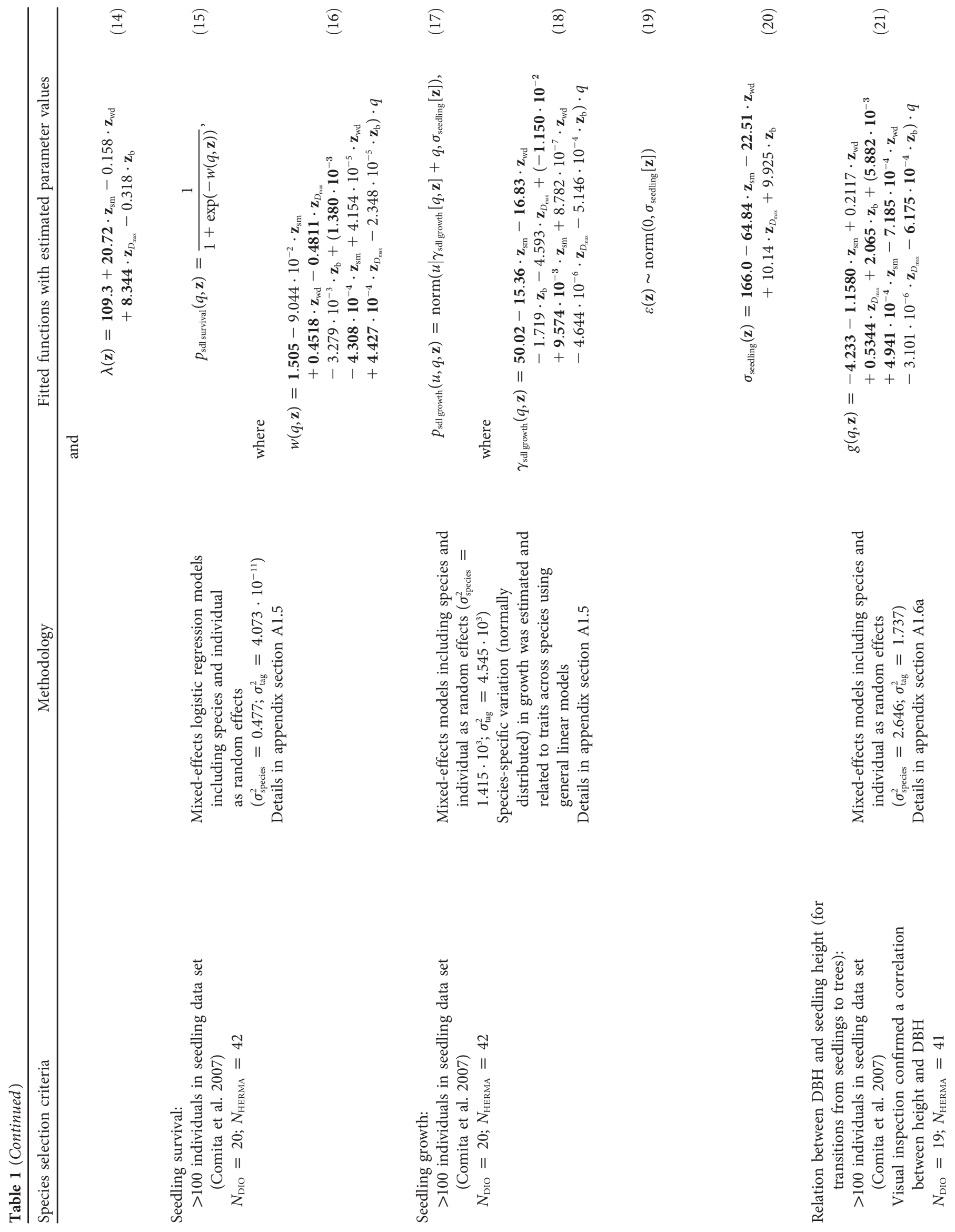

This content downloaded from 131.174.248.154 on July 28, 2017 05:21:42 AM 

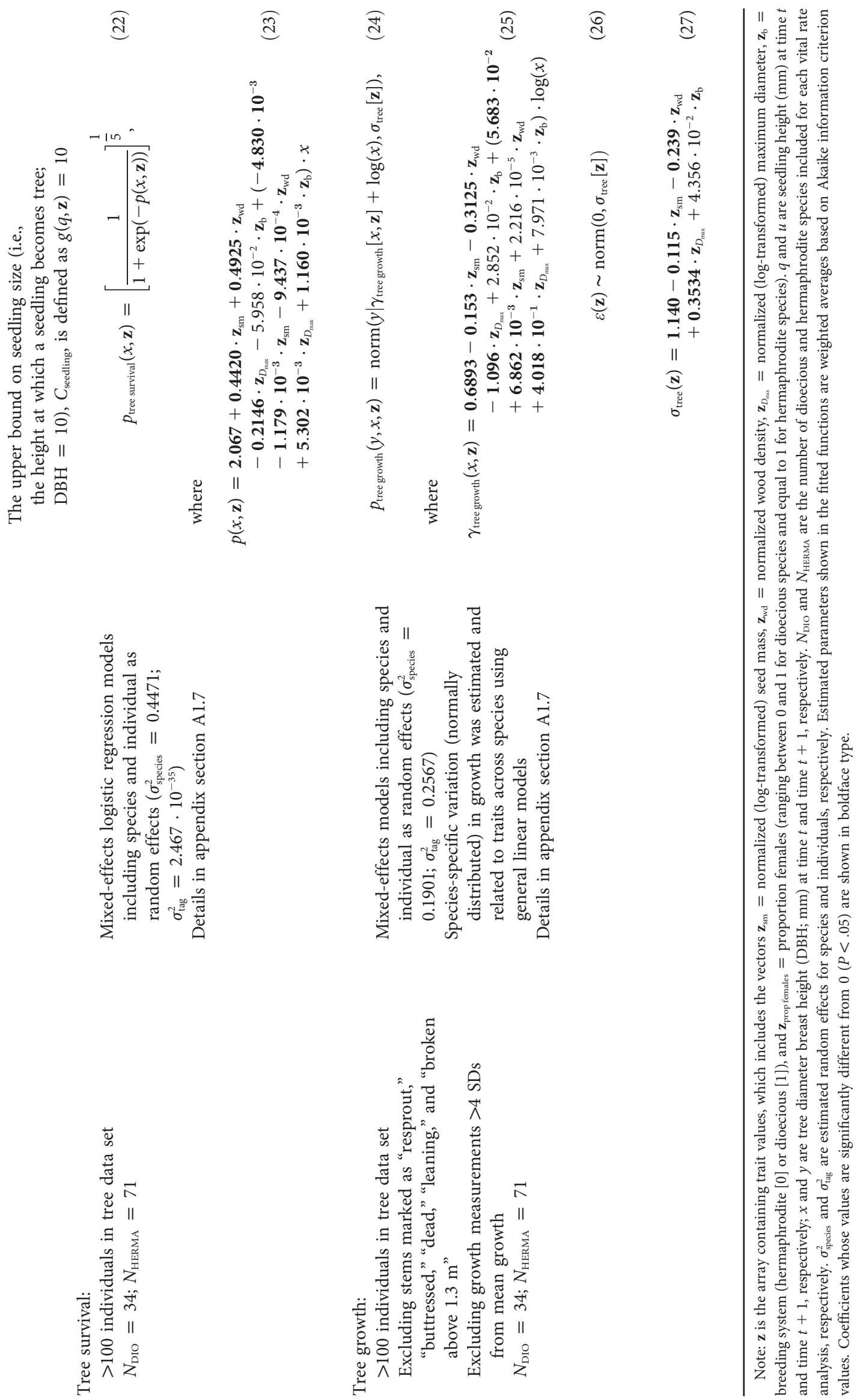

This content downloaded from 131.174.248.154 on July 28, 2017 05:21:42 AM 
the estimation of effect sizes, especially in cases where multiple variables influence the response variable (Grueber et al. 2011). Our normalized traits were only weakly correlated $\left(r_{\mathrm{SM}, \mathrm{WD}}^{2}=0.026 ; r_{\mathrm{SM}, D_{\max }}^{2}=0.021 ; r_{\mathrm{WD}, D_{\max }}^{2}=0.0019\right)$, and the statistical approach was also vigorously tested by Visser et al. (2016a), who, using the same vital rates and trait data, found no issues with nonlinearity, heteroscedasticity, nature of the random effect structure, and lack of random slopesissues that can potentially impact effect sizes and robustness of conclusions. Parameters were averaged over all models, using the zero method. This means that when a variable is not in a model, the parameter is assigned the value 0 . This is a conservative approach, leading to lower effect sizes (Burnham and Anderson 2002). Standard errors were calculated for all parameters of the weighted model, following Buckland et al. (1997). Analyses were performed with the lme4 package in R (Bates et al. 2013; R Core Team 2016).

The following three trait-dependent functions involved parameters calculated at the population level for each species: seed production $\left(f_{\text {seeds }}\right)$, seedling establishment $\left(p_{\text {establishment }}\right)$, and the shape and scale parameters of initial seedling size distributions ( $f_{\text {dist }}$; detailed methods are provided in app. secs. A1.1-A1.3; estimates for $f_{\text {seeds }}$ and $p_{\text {establishment }}$ are provided in suppl. secs. S2 and S3, respectively). For each of these species-level parameters, we used generalized linear models to fit all 16 possible models involving additive combinations of traits, with the most complex model being

$$
\text { species value } \sim B+\mathrm{SM}+\mathrm{WD}+D_{\max } \text {. }
$$

The six remaining trait-dependent functions involve parameters calculated at the individual level using all species simultaneously: reproductive status $\left(p_{\text {repr }}\right)$, seedling survival $\left(p_{\text {sdl survival }}\right)$, seedling growth $\left(p_{\text {sdl growth }}\right)$, tree survival $\left(p_{\text {tree survival }}\right)$, tree growth $\left(p_{\text {tree growth }}\right)$, and the relation between seedling $\mathrm{DBH}$ and height $(g)$. For these functions, we included effects of individual size (seedling height or tree $\mathrm{DBH}$ ), species traits, and interactions between size and traits (details in app. secs. A1.4-A1.7). We log transformed initial sizes in tree growth models. We used linear mixed-effects models with species and individual as random effects to fit models for all 82 possible combinations of traits and trait-size interactions, with the most complex model being

individual value $\sim$ size $\cdot B+$ size $\cdot \mathrm{SM}+$ size $\cdot \mathrm{WD}+$ size $\cdot D_{\max }$.

We additionally tested how well our model-averaged traitbased models captured interspecific variation by comparing trait-based model results with species-specific fits for each species individually and calculating $R^{2}$ values across species (suppl. sec. S4). We also tested whether the trait-based modelaveraging approach was capable of capturing the well- known growth-survival trade-off (Wright et al. 2010; suppl. sec. S5).

To test whether sex affected tree growth and whether sex ratios changed with size, we also fitted species-specific vital rate models for eight dioecious species for which we collected new data on individual reproduction status (see below). Tree growth was fitted as a linear model as a function of log-transformed $\mathrm{DBH}$, with sex as a factor influencing both slope and intercept. We tested for size dependency in sex ratios using logistic regressions of sex as a function of DBH. Finally, we fitted the probability of reproduction as a function of tree size (DBH) using logistic regression for each focal dioecious species.

\section{Study Site and Species}

Demographic data were collected in a moist tropical forest in the 50-ha forest dynamics plot (FDP) on BCI. BCI is a 1,562-ha island in central Panama. Annual rainfall averages $2,600 \mathrm{~mm}$, and there is a pronounced dry season between January and April (Leigh 1999). More information on BCI and associated data sets can be found in Croat (1978), Condit et al. (1999), and Leigh (1999).

\section{Tree, Seed, and Seedling Censuses}

All free-standing woody stems (hereafter, "trees") larger than $1 \mathrm{~cm}$ in DBH (measured at $1.3 \mathrm{~m}$ in height) were measured, tagged, mapped, and identified to species (in 19801982, 1985-2010 at 5-year intervals; Condit 1998). Data are deposited in the Smithsonian DSpace Repository: http:// dx.doi.org/10.5479/data.bci.20130603 (Condit et al. 2012). We excluded data from the first two censuses in analyses of tree growth and survival due to small but important differences in measurement methods (Condit 1998).

Fruit and seeds were identified to species in weekly censuses of two hundred $0.5-\mathrm{m}^{2}$ seed traps starting in January 1987 (details in Wright et al. 2005b). Fifty additional seed traps were established in newly formed canopy gaps between 2002 and 2004 (Puerta-Piñero et al. 2013). We use seed data from all 250 traps and inverse modeling (details in app. sec. A1.1) to estimate seed production for 2008 through 2012, which corresponds to our reproductive tree censuses (see "Reproductive Status Censuses"). Seed data are deposited in the Smithsonian DSpace Repository: http://dx .doi.org/10.5479/10088/29572 (Wright and Calderón 2016).

Seedlings and new recruits were tagged and identified to species in annual censuses of six hundred $1-\mathrm{m}^{2}$ plots starting in 1994 (details in Wright et al. 2005b). Our recruit size distributions and seed-to-seedling establishment probabilities are based on seedling recruits from 1995 through 2011 (Wright and Hernández 2016) and seed production for corresponding fruiting years (after accounting for speciesspecific germination delays; Wright et al. 2015b). 
All free-standing woody plants $\geq 20 \mathrm{~cm}$ tall and $<1 \mathrm{~cm}$ in $\mathrm{DBH}$ were tagged, measured for height, and identified to species in annual censuses of twenty thousand $1-\mathrm{m}^{2}$ seedling plots starting in 2001 (details in Comita et al. 2007; Visser et al. 2016a). Data are deposited in the Dryad Digital Repository: http://dx.doi.org/10.5061/dryad.fm654 (Visser et al. 2016b). We estimated seedling survival and growth and the allometric relationship between seedling height and DBH using the 2001, 2002, 2003, and 2004 censuses. In 2002, the status (alive or dead) of previously tagged seedlings was recorded, but height was measured only for newly recruited seedlings.

\section{Reproductive Status Censuses}

We combined three censuses of the reproductive status of individual trees. Data are available in the Smithsonian DSpace Repository: http://dx.doi.org/10.5479/si.data.2015 11251100 (Wright et al. 2015a). Between January 1995 and January 1996, we censused all individuals of 15 species in the FDP and subsampled 16 species (Wright et al. 2005a). Between April 2011 and January 2013, we subsampled 73 additional species. Between March and June 2012, we censused all individuals of eight dioecious species ( $\mathrm{Al}$ chornea costaricensis, Triplaris cumingiana, Virola sebifera, Pouteria reticulata, Protium tenuifolium, Cecropia insignis, Cecropia obtusofolia, and Simarouba amara). For species that were subsampled, trees were initially selected randomly from among those larger than estimated reproductive DBH thresholds and visited while flowering or fruiting. If trees of the estimated threshold size were reproductive, the minimum DBH threshold was lowered further. Reproductive status was evaluated from the ground, using binoculars where necessary, and was scored on a 5-point scale (details in Wright et al. 2005a). For dioecious species, sex expression was determined by viewing flowers in the crown using binoculars or examining abscised flowers on the ground. Flowering trees for which sex could not be determined were revisited during the fruiting season.

\section{Evaluating the Population-Level Effects of Dioecy}

We used the composite IPM to quantify the effects of dioecy on intrinsic population growth rates, $r(\ln (\lambda))$. We calculated $r$ for a hermaphroditic species with average trait values (normalized SM, WD, and $D_{\max }$ set to 0 ) and compared it to $r$ for a dioecious species with the same trait values assuming $p_{\text {female }}=0.5$ (incorporating dioecy effects on all vital rates; table 1$)$. The difference between these two intrinsic growth rates $(\Delta r)$ measures the net demographic effect of dioecy at average trait values. (For similar life cycle analyses, see Metcalf and Pavard 2007 and Visser et al. 2011.) For both breeding systems and for average trait values, we calculated the proportional sensitivity (elasticity) of these population growth rates to small perturbations in the stageand size-dependent vital rate functions using standard methods (de Kroon et al. 1986; Easterling et al. 2000). We also calculated per capita population growth rates for every trait combination observed among the BCI tree species included in our analyses and compared population growth rates between dioecious species and hermaphrodites.

We further used the composite IPM to separate the contributions of dioecy effects associated with different vital rates. To isolate the costs of having male individuals that do not produce seeds from any other differences in vital rates associated with dioecy, we calculated $r$ for a species with $p_{\text {female }}=0.5$ and all other vital rates equal to mean values observed for hermaphrodites. The change in intrinsic growth rate $(\Delta r)$ relative to a species with $p_{\text {female }}=$ 1 measures the demographic cost of simply halving the proportion of seed-producing individuals. To further explore how the demographic cost of males depends on sex ratio, we calculated $\Delta r$ with $p_{\text {female }}$ equal to the observed sex ratios of the eight focal dioecious species (table 2). Note that here we assume that a change in sex ratio does not change pollination dynamics, which may be frequency dependent.

We then used the breeding system coefficients shown in table 1 to change the value of one vital rate at a time, keeping all other rates at the hermaphroditic level, to the value observed for dioecious species with average trait values and recalculated $\Delta r$ relative to a hermaphroditic species with the same trait values. The difference between these two intrinsic growth rates quantifies the demographic impact (cost or benefit) of dioecy on this vital rate alone at average trait values.

We evaluated the robustness of these cost-benefit analyses given uncertainty in breeding system coefficients (intercept and, where relevant, slope). For each vital rate separately, we varied predictions up to $1 \mathrm{SD}$ away from their mean, constructed a new IPM, and recalculated $\Delta r$. To quantify uncertainty in the net effect, we sampled breeding system effects in all vital rates simultaneously. Coefficients were sampled from normal distributions with means and standard deviations estimated from model fits. We performed 100 resamples to calculate standard deviations for $\Delta r$.

To evaluate the extent to which costs and benefits of dioecy vary with trait values, we repeated the cost-benefit analysis for trait values up to $1 \mathrm{SD}$ away from the mean for each trait separately. Finally, we calculated the sensitivity of $r$ for changes in SM, WD, and $D_{\max }$ (details in suppl. sec. S6).

\section{Results}

For each vital rate, the average model is given in table 1 , and the five best-performing models (based on AIC), weighted coefficients, standard errors, and random effects variances are given in supplement section S7. Note that model aver- 
Table 2: Numbers of observed males and females of eight dioecious species for which sex information was collected

\begin{tabular}{lccccccc}
\hline & Minimum & No. & No. & $\begin{array}{c}\text { No. } \\
\text { sterile } \\
\text { trees }\end{array}$ & $\begin{array}{c}\text { Proportion } \\
\text { female }\end{array}$ & $\begin{array}{c}\text { Reproduction } \\
\text { intercept }\end{array}$ & $\begin{array}{c}\text { Reproduction } \\
\text { slope }\end{array}$ \\
\hline Alchornea costaricensis & 67 & 47 & 36 & 59 & $.57(.47-.67)$ & $-3.12 \pm .619$ & $.013 \pm .0025$ \\
Cecropia insignis & 11 & 102 & 118 & 97 & $.46(.40-.53)$ & $-2.009 \pm .368$ & $.021 \pm .0030$ \\
Cecropia obtusifolia & 10 & 47 & 64 & 25 & $.42(.34-.52)$ & $.852 \pm .404$ & $.008 \pm .0035$ \\
Simarouba amara & 100 & 31 & 32 & 71 & $.49(.37-.61)$ & $-5.963 \pm 1.023$ & $.019 \pm .0035$ \\
Pouteria reticulata & 100 & 38 & 56 & 107 & $.40(.31-.51)$ & $-3.918 \pm .566$ & $.012 \pm .0019$ \\
Protium tenuifolium & 67 & 97 & 121 & 348 & $.44(.38-.51)$ & $-3.601 \pm .290$ & $.019 \pm .0017$ \\
Triplaris cumingiana & 60 & 46 & 34 & 51 & $.58(.47-.68)$ & $-2.274 \pm .573$ & $.017 \pm .0036$ \\
Virola sebifera & 67 & 58 & 116 & 244 & $.33(.27-.41)$ & $-4.271 \pm .449$ & $.019 \pm .0021$ \\
\hline
\end{tabular}

Note: All individuals in the 50-ha plot larger than the listed species-specific minimum diameter breast height (DBH) thresholds were visited. The proportion female is given with binomial confidence intervals. Logistic regressions were used to estimate the relation between DBH and species-specific reproductive probability (combining males and females). Estimated coefficients ( $\pm 1 \mathrm{SE}$ ) are given; larger trees are significantly more likely to be reproductive in all species.

aging was done over all included models and that parameter values that are given below are weighted parameters over all models.

\section{Sex Ratios and Reproductive Probability}

The proportion of female individuals averaged 0.46 among the eight dioecious species with sex expression data (table 2). Triplaris cumingiana had the strongest female bias (0.57), and Virola sebifera had the strongest male bias (0.33). We found no consistent pattern of size dependency of sex ratios, with three species showing a negative relationship between DBH and proportion females and one species showing a positive relationship (suppl. sec. S8). Reproductive probability increased significantly with DBH for all eight species (table 2).

The trait-based probability of reproduction $\left(p_{\text {repr }}(x, \mathbf{z})\right)$ was unaffected by breeding system (fig. $2 a$ ). The best model did not include breeding system, and the total weight of models including breeding system was 0.32 . The average model predicted a difference of just $1 \mathrm{~mm}$ in the $\mathrm{DBH}$ at which reproductive probability reached $50 \%$ for hermaphroditic and dioecious species, and the narrow confidence intervals for relevant parameters included 0 (see fig. $2 a$, eq. [8] in table 1, and table S7.2; supplemental tables are available online). Observed species-specific values were well predicted by the average model (fig. S4.1; supplemental figures are available online; $R^{2}=0.49$ using only fixed effects).

\section{Seed Production and Dispersal}

Seed production $\left(f_{\text {seeds }}(x, \mathbf{z})\right)$ was significantly larger for dioecious than hermaphroditic species, supporting the first hypothesis for compensatory benefits of dioecy (figs. $2 b, 3 a$ ). The summed weight of all models including breeding system was 0.75 , and dioecious species had higher seed produc- tion in the average model (effect DIO: $0.67 \pm 0.26 \mathrm{SE}$; eq [10] in table 1; table S7.4). The estimated effect in the average model implies that female individuals of dioecious species produce $95 \%$ more seeds per unit of reproductive basal area than hermaphrodites when controlling for seed mass and other species traits (calculated as $\mathrm{e}^{0.67}$; see eqq. [9], [10] in table 1). The average model included a strong negative effect of seed mass $(-1.47 \pm 0.12 \mathrm{SE})$, a weak negative effect of $D_{\max }(-0.649 \pm 0.20 \mathrm{SE})$, and a weaker (insignificant) positive effect of WD $(0.075 \pm 0.075 \mathrm{SE})$ on seed production. Species-level variation was well explained by the average model $\left(R^{2}=0.77\right.$; fig. $\left.3 a\right)$. There were no consistent differences in seed dispersal distances between hermaphrodite and dioecious species (suppl. sec. S2).

\section{Seedling Establishment, Growth, and Survival}

For seedling establishment $\left(p_{\text {establishment }}(\mathbf{z})\right)$, the total weight of models including breeding system was 0.38 , and the full average model explained species-level variation relatively well $\left(R^{2}=0.62\right.$; fig. $\left.3 b\right)$. The estimated seed-to-seedling transition probability was $3.73 \%$ for hermaphroditic species and $3.27 \%$ for dioecious species at average trait values (eq. [11] in table 1; table S7.10), thereby predicting $12 \%$ lower seedling establishment in dioecious than in hermaphroditic species (calculated as $1-3.27 / 3.73$ ). However, the confidence interval for the dioecy effect included 0 (effect DIO: $-0.13 \pm 0.12 \mathrm{SE}$ ).

For seedling growth $\left(p_{\text {sdl growth }}(q, u, \mathbf{z})\right)$, the total weight of models including breeding system was 0.92 . Both uncertainty (fig. $2 d$ ) and variation in species and individual random effects were large (tables 1, S7.12). The average model (using fixed effects only) predicted greater seedling growth rates for hermaphroditic than dioecious species over all 

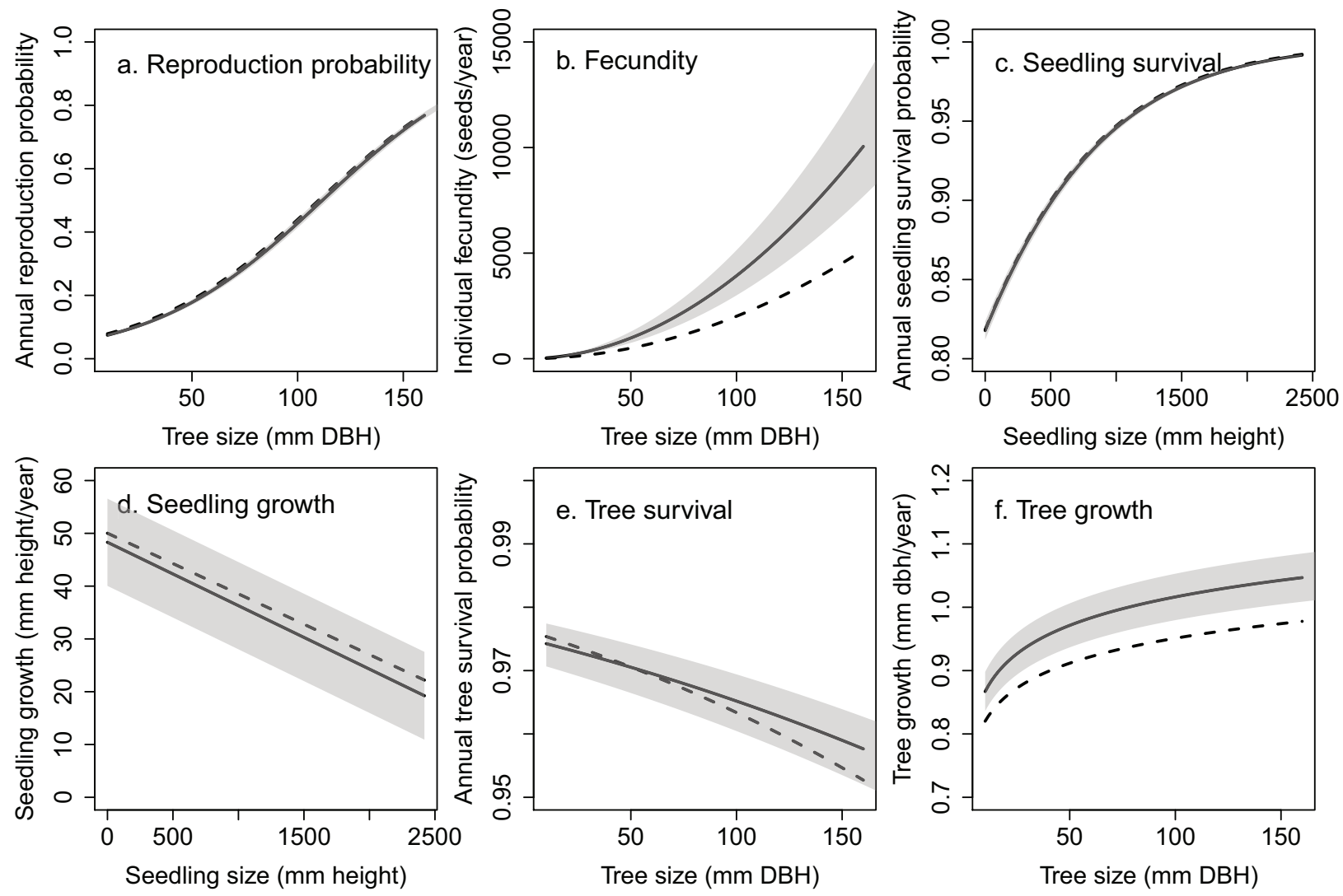

Figure 2: Comparisons of estimated size-dependent vital rates between hypothetical hermaphroditic (dotted line) and dioecious (solid line) tree species having identical community average values of seed mass (SM), wood density (WD), and maximum size $\left(D_{\text {max }}\right)$, with uncertainty in the dioecy effect (gray shading shows $\pm 1 \mathrm{SD}$ ), as calculated from the trait-dependent models fitted to combined data for many tropical tree species (table 1). In $a, b, e$, and $f$, sizes range between diameter breast height (DBH) of 10 and 158 mm, the maximum DBH for an average species $\left(D_{\max }\right.$ set to 0$)$. $C_{\text {seedling }}$ equals $2,420 \mathrm{~mm}$ in height for an average species and is the seedling height at which a seedling is predicted to have a $\mathrm{DBH}$ of $10 \mathrm{~mm}$ and enter the tree stage.

seedling sizes (fig. 2d), although the wide confidence intervals for the dioecy effect include 0 (effect DIO: $-1.72 \pm$ 8.26 SE). Only a small proportion of observed interspecific variation was explained by the average model (fig. S4.3, $R^{2}=0.08$ using only fixed effects).

For seedling survival $\left(p_{\text {sdl survival }}(q, \mathbf{z})\right)$, the total weight of models including breeding system was 0.38 . The average model (using fixed effects only) predicted very similar seedling survival for hermaphroditic and dioecious species, and the narrow confidence intervals for the dioecy effect included 0 (see fig. $2 c$; table S7.14). The average model predicted observed species-level values reasonably well (fig. S4.2; $R^{2}=$ 0.29 using only fixed effects).

\section{Tree Growth and Survival}

For tree growth $\left(p_{\text {tree growth }}(y, x, z)\right)$, the total weight of models including breeding system was 0.50 . The average model (us- ing fixed effects only) predicted observed species-level values well (fig. S4.5; $R^{2}=0.53$ ). The average model predicted greater tree growth rates for dioecious than hermaphroditic species (effect DIO: $0.0285 \pm 0.030 \mathrm{SE}$ ), with the absolute growth advantage associated with dioecy increasing with size (effect DIO $\times \log ($ size $): 0.00797 \pm 0.00497 \mathrm{SE})$, but confidence intervals include 0 for both the additive effect of breeding system and the size $\times$ breeding system interaction (fig. $2 f$ ). The average model predicts annual $\mathrm{DBH}$ growth rates at $100 \mathrm{~mm} \mathrm{DBH}$ of 0.95 and $1.02 \mathrm{~mm}$ per year for hermaphroditic and dioecious species, respectively (eq. [25] in table 1; table S7.20).

For tree survival $\left(p_{\text {tree survival }}(x, \mathbf{z})\right)$, the total weight of models including breeding system was 1.00 . The average model (using fixed effects only) predicted observed specieslevel values reasonably well (fig. S4.4; $R^{2}=0.29$ ). The average model predicted a decreased intercept for dioecious species (effect DIO: $-0.0596 \pm 0.142$ SE) and an increased 

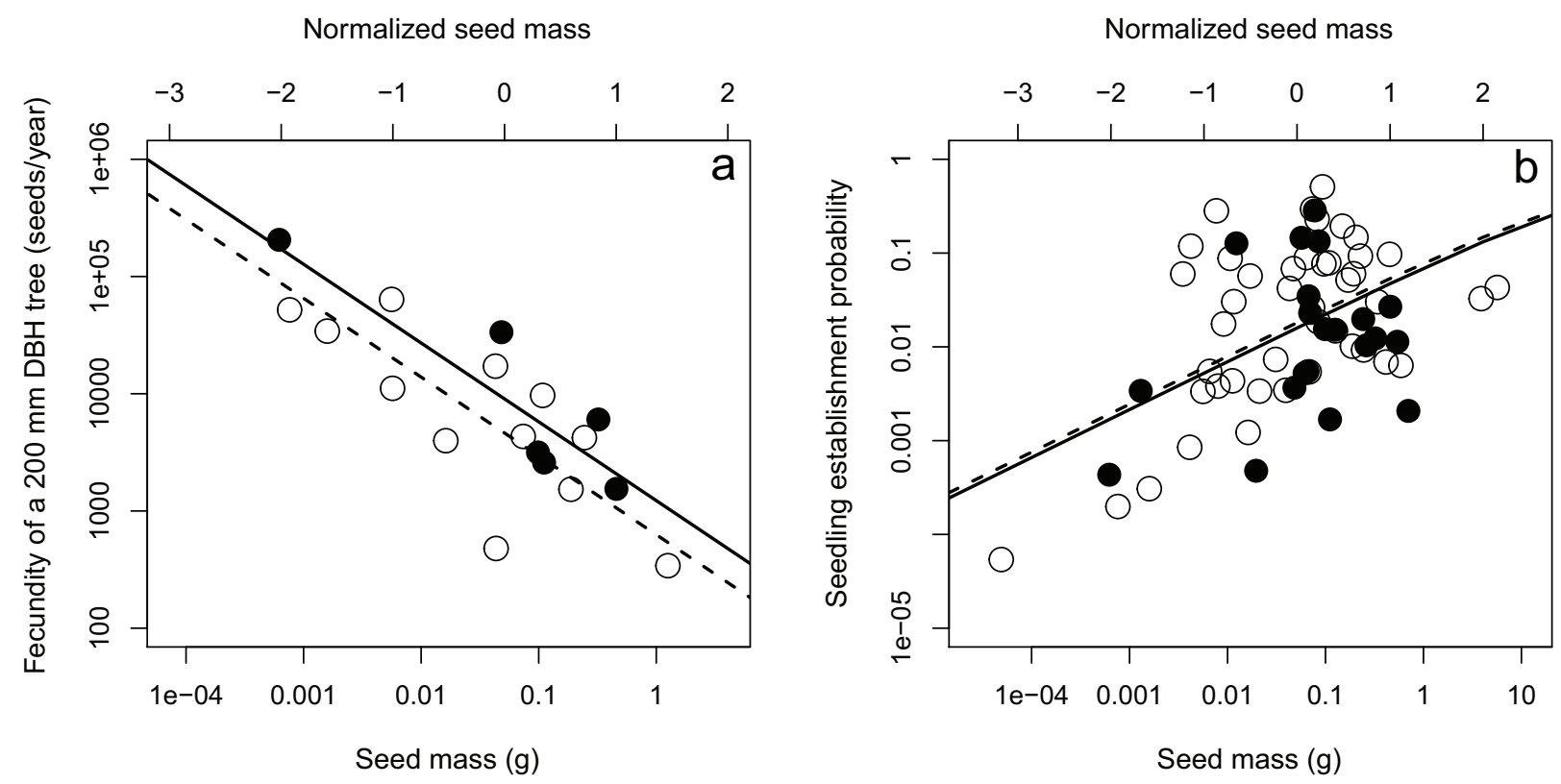

Figure 3: Species-specific estimated seed production $(a)$ and seedling establishment probability $(b)$ versus seed mass for dioecious (filled circles, solid lines) and hermaphroditic (open circles, dashed lines) tree species. Plotted fecundities are standardized to those estimated for a fully reproductive tree with a diameter breast height (DBH) of $200 \mathrm{~mm}$. Lines represent the fitted average models including all traits for dioecious (solid line) and hermaphroditic (dashed line) species for average wood density and maximum size $\left(D_{\max }\right)$.

slope (effect DIO $\times \log ($ size $): 0.00116 \pm 0.000140 \mathrm{SE})$; note that the confidence interval for the effect of dioecy on the intercept effect easily overlaps 0 , while the narrow confidence interval on the slope does not come close to overlapping 0 (fig. 2e). This indicates that for species with average $D_{\max }$, trees do not reach the sizes at which dioecy provides a demographic benefit (fig. 2e). For average trait values, the model predicted annual survival probabilities at $100 \mathrm{~mm} \mathrm{DBH}$ of 0.963 and 0.965 for hermaphroditic and dioecious species, respectively (eqq. [22], [23] in table 1; table S7.22). However, differences in estimated survival become more pronounced at larger sizes. When $D_{\max }$ is set at 1 , predicted yearly survival probability of a tree with a $\mathrm{DBH}$ of $400 \mathrm{~mm}$ is 0.976 for a hermaphroditic species, while it is 0.984 for a dioecious species.

When we included the sex of individuals as a factor in species-specific growth models, we found no consistent patterns across species and individually significant effects in only two species: Alchornea costaricensis had a decreased slope in males, while Pouteria reticulata had an increased slope in males (suppl. sec. S9).

\section{Population-Level Effects of Dioecy}

For average trait values, intrinsic growth rate $r(\ln (\lambda))$ based on the composite IPM was 0.0176 per year for hermaphrodites, compared with 0.0179 per year for dioecious species with $50 \%$ males. Population growth rates $\lambda$ were 1.0179 and 1.0180, respectively, suggesting annual increases of $1.78 \%$ for hermaphrodite and $1.80 \%$ for dioecious species. Elasticity values were largest for tree stages $P_{\text {tree }}(y, x, \mathbf{z})$ (HERMA: 0.69; DIO: 0.66), intermediate for seedling stages $P_{\text {seedling }}(u, q, \mathbf{z})$ and $P_{\text {new tree }}(y, q, \mathbf{z})$ (HERMA: 0.31 ; DIO: 0.33$)$, and very small for reproduction $F(u, x, \mathbf{z})$ (HERMA: 0.01; DIO: 0.009). When constructing IPMs using combinations of trait values (WD, $\mathrm{SM}$, and $D_{\max }, \mathrm{B}$ ) observed for real species occurring on BCI, 95\% of the simulated intrinsic growth rates ranged between -0.029 and 0.032 for hermaphrodites and between -0.0082 and 0.022 for dioecious species, indicating fairly stable populations overall.

When the effects of dioecy on individual vital rates were evaluated at average trait values for $\mathrm{SM}, \mathrm{WD}$, and $D_{\max }$, we found that the largest cost of dioecy was the presence of non-seed-producing individuals (males) in the population (fig. $4 a$; gray circles indicate effects for average trait values). All else equal, having 50\% males decreased the intrinsic growth rate $r$ by 0.00652 , translating to a shift from a $1.78 \%$ annual increase to a $1.11 \%$ annual increase. Smaller costs were found when adding the dioecious-specific decrease in seedling establishment and seedling growth (decreasing $r$ by 0.00125 and 0.00037 , respectively). The largest benefit associated with dioecy was increased seed production in dioecious females compared with hermaphrodites, 


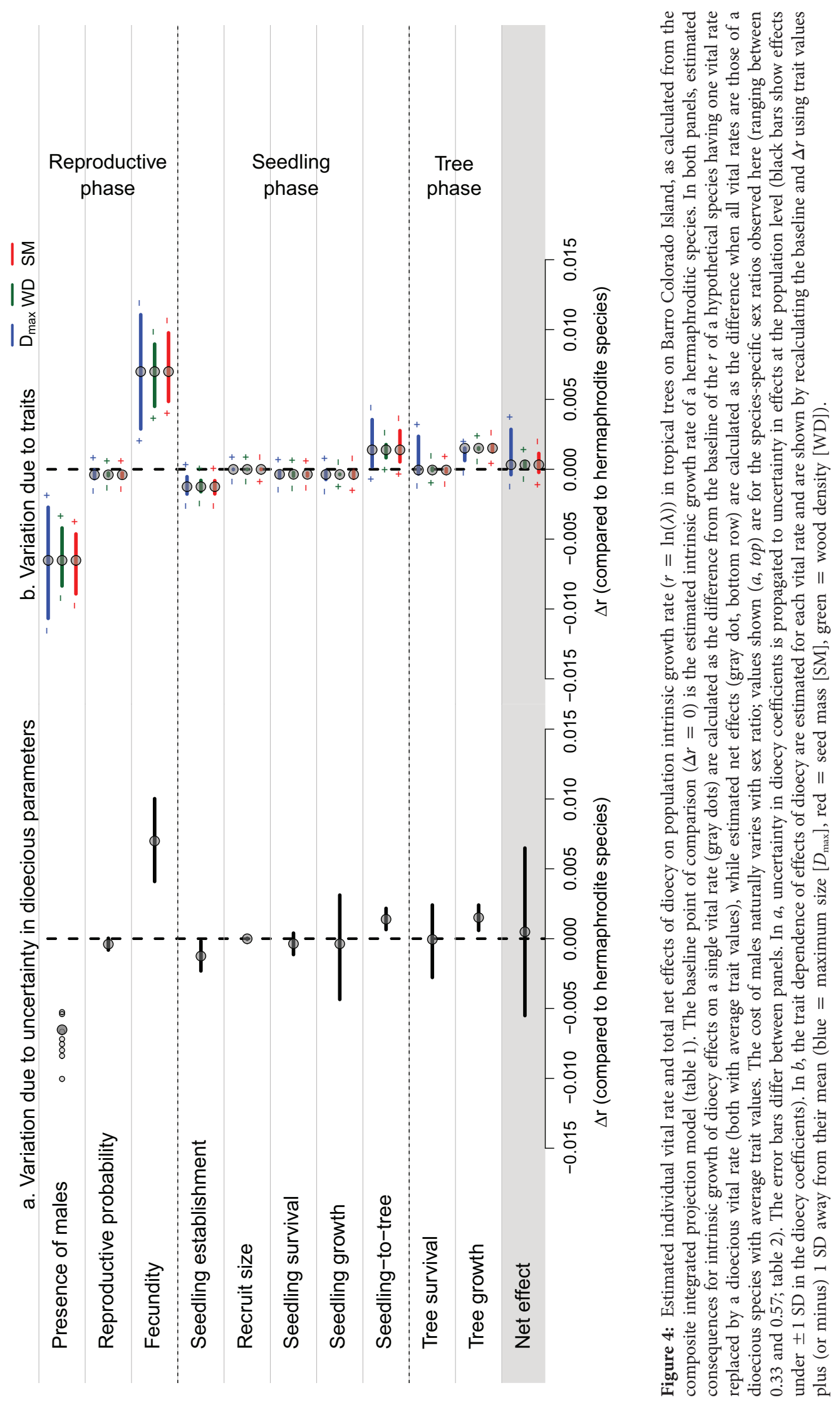

This content downloaded from 131.174.248.154 on July 28, 2017 05:21:42 AM 
resulting in an increase of 0.00699 in $r$. The second largest benefit associated with dioecy concerned tree growth, resulting in an increase of 0.00151 in $r$. Total estimated benefits compensate for total estimated costs in the model parameterized for dioecious species with a sex ratio of $50 \%$ (total $\Delta r=0.0000321$, which represents a shift from $+1.78 \%$ to $+1.80 \%$ annual population growth). Sex ratio had the predictable effect of inflating costs with increasing male bias; for observed sex ratios, $\Delta r$ ranged between -0.00526 ( $57 \%$ females) and -0.010 (33\% females; gray dots in upper row in fig. $4 a$ ).

When integrating uncertainty in breeding system effects in the IPMs, we found that many effects on the population growth rate included 0 within $1 \mathrm{SD}$ (fig. $4 a$ ). Indeed, the sole effects that were significantly different from 0 were the presence of males and the enhanced seed production in females. When incorporating uncertainty in dioecious parameters across all vital rates, the net effect on a population level included 0 within 1 SD (bottom row in fig. $4 a$ ).

The estimated effects of dioecy on population growth rates differed systematically with functional traits in many cases (fig. $4 b$; suppl. sec. S6). The overall effects of dioecy varied most strongly with maximum adult stature $\left(D_{\max }\right)$. Larger stature was associated with lower costs for having males, lower benefits in seed production, higher benefits in tree survival, lower benefits in seedling transition, and more positive overall net effects. Individual demographic costs and benefits also varied to a lesser degree with seed mass (SM) and wood density (WD), but net effects were little affected. Higher values of SM and WD were associated with lower costs for males and lower benefits in seed production.

\section{Discussion}

Our study provides the most complete quantification to date of the various demographic costs and benefits of dioecy relative to hermaphroditism, based on 20 years of demographic data on the BCI tree community. Our evaluation with a composite IPM that accounted for the effects of three other key life-history traits suggested that, on average, the demographic benefits offset the costs when integrated over all life stages, as one might expect based on the continued persistence of dioecious species. We show that there are both benefits and costs at different life stages, with strikingly different elasticities. Benefits or costs at a single stage were not indicative of total population-level effects, illustrating the importance of full life cycle analyses. In our populationlevel analyses, the main cost associated with dioecy was the reduced number of seed-producing trees, and the largest benefit was the greater seed production of dioecious females. Our best estimates of dioecy effects suggest that dioecious species benefit from increased seed production (sup- porting hypothesis 1) and, to a lesser extent, tree growth and survival (supporting hypotheses 5 and 6) but do not benefit from increased seedling establishment, seedling growth, or seed survival (contrary to hypotheses 2-4). Interestingly, costs and benefits were estimated to vary considerably depending on other species traits, with large-statured species in particular estimated to have more positive net effects of dioecy (fig. $4 b$ ).

Despite the large data sets brought to bear here, there remained considerable uncertainty in all estimated effects of dioecy (figs. 2, 4a). We interpret this as reflecting not only the inherent noisiness of demographic data but also the fundamentally small size of the effects of dioecy on population growth rates in comparison with other factors. On both a population and a vital rate level, the demographic effects of breeding system were relatively small compared with the effects of SM, WD, and $D_{\max }$ (fig. S6.1 and coefficients in table 1). Moreover, a substantial proportion of vital rate variance was captured by the random effects for species (suppl. sec. S7), indicating an important role for other unmeasured traits and trait-environment interactions (see also Visser et al. 2016a). This is consistent with the idea that factors influencing reproduction should have a relatively small impact on long-lived organisms (Visser et al. 2011), an issue discussed further below.

\section{Variation in Sex Ratios}

For six of eight dioecious species, we observed more reproductive males than females, which is in accordance with the general finding of male-biased populations in dioecious tropical forest trees (Opler and Bawa 1978; Queenborough et al. 2007). However, this male bias was statistically significant in only one species, Virola sebifera (116 males; 58 females), which belongs to a genus and family (Myristicaceae) previously shown to contain male-biased species (Queenborough et al. 2007). Triplaris cumingiana was found to be female-biased (although not significantly), in accordance with studies of a congener, Triplaris americana (Bawa 1977; Melampy and Howe 1977). We found no consistent patterns in the size dependency of sex ratios across these eight species (suppl. sec. S8), in agreement with Queenborough et al. (2007).

\section{Seed Production}

Dioecious species are hypothesized to produce more seeds per female than do hermaphroditic species because they do not invest in male flowers (Heilbuth et al. 2001; Barot and Gignoux 2004; Vamosi et al. 2008). Consistent with this hypotheses, females in gynodioecious species, which have both females and hermaphrodites (Bawa and Beach 1981), produce up to $70 \%$ more seeds than do hermaphrodites 
(Ashman 1994, 1999; Asikainen and Mutikainen 2003; Spigler and Ashman 2012). However, evaluation of this hypothesis for purely dioecious species is more difficult. Ours is the first study to compare seed production of dioecious and hermaphroditicspecies while correcting for the well-known tradeoff between seed number and seed mass (Moles et al. 2004; Muller-Landau et al. 2008).

Our results suggest that dioecious species indeed benefit from higher seed production. Dioecious females produced on average $95 \%$ more seeds than did hermaphrodites, after controlling for seed size. On a population level, this increase is almost enough to fully compensate the loss of seeds due to the presence of males. Confidence intervals for this increased seed production were quite large, with $95 \%$ confidence intervals encompassing increases of $16 \%$ to $228 \%$. Despite this uncertainty, increased seed production remained a confirmed benefit at the population level after integrating all effects and uncertainty (fig. $4 a$ ). Overall, our seed production estimates fall in the same range as previous estimates for these species, estimates that incorporated data for more years but did not benefit from information on which trees were female (Muller-Landau et al. 2008).

\section{Seedling Phase}

Even a doubling of the number of seeds produced per female might be insufficient to compensate for the full costs of dioecy due to increased local competition or increased attack by density-dependent natural enemies, such as pathogens and insect herbivores (Heilbuth et al. 2001; Barot and Gignoux 2004). Increased local competition and natural enemy attack is predicted among seedlings of dioecious species because they are expected to be more aggregated in space around females, and aggregation leads to decreased seedling performance (Harms et al. 2000; Comita et al. 2014; Lebrija-Trejos et al. 2014). Dioecious species, through increased seed production per mother tree, are therefore expected to have a "seed-shadow handicap" that limits the benefit of increased local seed production (Heilbuth et al. 2001; Barot and Gignoux 2004). It has been hypothesized that dioecious species might thus allocate for increased seed dispersal (Heilbuth et al. 2001), but we found no consistent differences in dispersal distances between dioecious and hermaphroditic species (suppl. sec. S2). Consistent with the seed shadow handicap hypothesis, our average model estimates of dioecy effects on seedling establishment, growth, and survival are negative, but these effects are highly uncertain and not significantly different from 0 (table 2; figs. $2 d$, $3 b$ ). The low elasticity for these vital rates meant that estimated population level costs were, in any case, small (fig. 4a). Note that elasticity values may be sensitive to sex ratio (Haridas et al. 2014), something we could not evaluate with a single-sex model.

\section{Tree Phase}

Dioecious species had greater growth and survival in the tree phase, and the advantage over hermaphroditic species increased with individual size (fig. $2 e, 2 f$ ). Greater growth and survival in dioecious species is expected if resource allocation to reproduction is reduced because individuals produce only one type of reproductive organ (Bawa 1980). Therefore, an increase in growth and survival should occur only after trees start reproducing. This suggests that any breeding system effects in terms of increased tree growth and survival are visible only at large tree sizes, which is supported by our results, as reflected by the increased slope (fig. $2 e, 2 f$ ). As a result of this benefit becoming more pronounced at larger sizes, the cost-benefit analysis found a strong survival benefit for dioecy for tree species whose maximum adult size was considerably above the average (DBH of $158 \mathrm{~mm}$ ), despite the lack of such a benefit for species of average or below-average size (fig. $4 b$ ).

The estimated effects of dioecy on tree growth and survival were highly uncertain (fig. $2 e, 2 f$ ). One possible cause of this uncertainty could be sex-specific effects of individuals. It seems unlikely that dioecious females could increase seed production and simultaneously increase tree growth and/or survival. One hypothesis to explain these findings is that the increased seed production may be a female effect, while the increased growth and survival could be largely a male effect. However, we found no consistent sex differences in growth (suppl. sec. S9). This is in agreement with Queenborough et al. (2007), who found no significant sex effects on annual diameter growth in 12 tropical tree species in Ecuador. Tests of the hypothesis remain inconclusive, as we could not account for potential spatial segregation of the sexes, which has been found in some previous studies (Cox 1981; Bierzychudek and Eckhart 1988; Queenborough et al. 2007; Forero-Montaña et al. 2010; Ortiz-Pulido and Pavon 2010). When males occur more frequently in less suitable habitats, sex-specific survival and growth benefits may be obscured.

\section{Balance of Costs and Benefits}

Our population models project that the intrinsic population growth rate of an average hermaphroditic species is 0.0176 per year, compared with 0.0178 for a dioecious species with the same trait values and a 50\% sex ratio. This suggests that the combined demographic costs are compensated by fitness advantages in other aspects of the life history of dioecious species, although there is considerable uncertainty in estimates of individual vital rate and total effects (figs. 2-4). After integrating breeding system effects across the full life cycle, increased seed production was the most important and only significant compensating factor (fig. $4 a$ ). 
The presence of males was the strongest cost of dioecy. For average trait values, our population-level cost-benefit analysis shows that the presence of males, when the sex ratio was $50 \%$, reduced the intrinsic growth rate $r$ by 0.00652 . It is generally assumed that dioecy as a breeding system comes with demographic costs, and intuitively this makes sense. Our results show not only that the increased seed production compensates for these costs but also that the inherent costs are low to begin with. This is because for longlived organisms such as trees, we expect low $\lambda$ elasticities for factors involving reproduction (de Kroon et al. 2000), as was also shown for reproductive strategies such as mast fruiting in tropical trees (Visser et al. 2011).

At global and regional scales, the proportion of species that are dioecious within plant communities varies greatly but tends to be higher in tropical than in temperate forests (Vamosi and Queenborough 2010). Multisite studies that similarly quantify the costs and benefits of breeding systems at the population level would help explain this wide variation in the success of the dioecious breeding system. In conclusion, our results support the hypotheses that the advantages of dioecy include increased seed production by females and, to a lesser extent, increased adult growth and adult survival. Together the benefits compensate for the costs of dioecy, which are found to be smaller than generally assumed because of the low elasticity of population growth rates to seed production in long-lived tree species.

\section{Acknowledgments}

S. Queenborough, T. Takada, and two anonymous reviewers greatly improved the manuscript. We are grateful for the assistance of D. Brassfield and A. Cerezo in collecting data on reproductive status. This research was partly supported by the Netherlands Organization for Scientific Research (NWO; grants 801-01-009 and 840-11-001 to E.J. and M.D.V.), the Smithsonian Tropical Research Institute, and the Smithsonian Institution Competitive Grants for Science (to H.C.M. and S.J.W.). The Barro Colorado Island forest dynamics research project was founded by R. B. Foster and S. P. Hubbell and is now managed by R. Condit, S. Lao, and R. Pérez under the Center for Tropical Forest Science and the Smithsonian Tropical Research Institute in Panama. Numerous organizations have provided funding, principally the US National Science Foundation, and hundreds of field-workers have contributed. Seedling data collection was funded by US National Science Foundation grants DEB-1242622, DEB0075102, DEB-0640386, and DEB-0823728.

\section{Literature Cited}

Armstrong, J. E., and A. K. Irvine. 1989. Flowering, sex ratios, pollenovule ratios, fruit set, and reproductive effort of a dioecious tree,
Myristica insipida (Myristicaceae), in two different rain forest communities. American Journal of Botany 76:74-85.

Ashman, T.-L. 1994. Reproductive allocation in hermaphrodite and female plants of Sidalcea oregana ssp. spicata (Malvaceae) using four currencies. American Journal of Botany 81:433-438.

. 1999. Determinants of sex allocation in a gynodioecious wild strawberry: implications for the evolution of dioecy and sexual dimorphism. Journal of Evolutionary Biology 12:648-661.

Asikainen, E., and P. Mutikainen. 2003. Female frequency and relative fitness of females and hermaphrodites in gynodioecious Geranium sylvaticum (Geraniaceae). American Journal of Botany 90:226-234.

Barot, S., and J. Gignoux. 2004. How do sessile dioecious species cope with their males? Theoretical Population Biology 66:163-173.

Barrett, S. C. H. 2010. Understanding plant reproductive diversity. Philosophical Transactions of the Roval Societv B 365:99-109.

Bates, D., M. Maechler, and B. Bolker. 2013. Lme4: linear mixedeffects models using S4 classes (R package version 0.999999-2).

Bawa, K. S. 1974. Breeding systems of tree species of a lowland tropical community. Evolution 28:85-92.

1977. Spatial relationships between staminate and pistillate plants of dioecious tropical forest trees. Evolution 31:64-68. 1980. Evolution of dioecy in flowering plants. Annual Review of Ecology and Systematics 11:15-39.

Bawa, K. S., and J. H. Beach. 1981. Evolution of sexual systems in flowering plants. Annals of the Missouri Botanical Garden 68:254274.

Bierzychudek, P., and V. Eckhart. 1988. Spatial segregation of the sexes of dioecious plants. American Naturalist 132:34-43.

Bolker, B. M., M. E. Brooks, C. J. Clark, S. W. Geange, J. R. Poulson, M. H. H. Stevens, and J. S. S. White. 2009. Generalized linear mixed models: a practical guide for ecology and evolution. Trends in Ecology and Evolution 24:127-135.

Buckland, S. T., K. P. Burnham, and N. H. Augustin. 1997. Model selection: an integral part of inference. Biometrics 53:603-618.

Burnham, K. P., and D. R. Anderson. 2002. Model selection and multimodel inference: a practical information-theoretic approach. Springer, New York.

Cade, B. S. 2015. Model averaging and muddled multimodel inferences. Ecology 96:2370-2382.

Caswell, H. 2001. Matrix population models: construction, analysis and interpretation. Sinauer, Sunderland, MA.

Charlesworth, B. 1980. Evolution in age-structured populations. Cambridge University Press, Cambridge.

Charlesworth, D. 2002. Plant sex determination and sex chromosomes. Heredity 88:94-101.

Comita, L. S., S. Aguilar, R. Pérez, S. Lao, and S. P. Hubbell. 2007. Patterns of woody plant species abundance and diversity in the seedling layer of a tropical forest. Journal of Vegetation Science 18:163-174.

Comita, L. S., H. C. Muller-Landau, S. Aguilar, and S. P. Hubbell. 2010. Asymmetric density dependence shapes species abundances in a tropical tree community. Science 329:330-332.

Comita, L. S., S. A. Queenborough, S. J. Murphy, J. L. Eck, K. Xu, M. Krishnadas, N. Beckman, et al. 2014. Testing predictions of the Janzen-Connell hypothesis: a meta-analysis of experimental evidence for distance- and density-dependent seed and seedling. Iournal of Ecology 102:845-856.

Condit, R. 1998. Tropical forest census plots. Springer, Berlin, and R. G. Landes, Georgetown, TX. 
Condit, R., P. S. Ashton, N. Manokaran, J. V. LaFrankie, S. P. Hubbell, and R. B. Foster. 1999. Dynamics of the forest communities at Pasoh and Barro Colorado: comparing two 50-ha plots. Philosophical Transactions of the Roval Society B 354:17391748.

Condit, R., S. Lao, R. Pérez, S. B. Dolins, R. B. Foster, and S. P. Hubbell. 2012. Barro Colorado forest census plot data (version 2012). Center for Tropical Forest Science Databases. Smithsonian DSpace Repository, http://dx.doi.org/10.5479/data.bci.20130603.

Cox, P. A. 1981. Niche partitioning between sexes of dioecious plants. American Naturalist 117:295-307.

Croat, T. B. 1978. Flora of Barro Colorado Island. Stanford University Press, Palo Alto, CA.

Darwin, C. 1877. The different forms of flowers on plants of the same species. Cambridge University Press, Cambridge.

de Kroon, H., A. Plaisier, J. van Groenendael, and H. Caswell. 1986 Elasticity: the relative contribution of demographic parameters to population growth rate. Ecology 67:1427-1431.

de Kroon, H., J. van Groenendael, and J. Ehrlén. 2000. Elasticities: a review of methods and model limitations. Ecology 81:607-618.

Easterling, M. R., S. P. Ellner, and P. M. Dixon. 2000. Size-specific sensitivity: applying a new structured population model. Ecology 81:694-708.

Ehrlén, J. 2003. Fitness components versus total demographic effects: evaluating herbivore impacts on a perennial herb. American Naturalist 162:796-810.

Ellner, S. P., and M. Rees. 2006. Integral projection models for species with complex demography. American Naturalist 167:410-428.

Forero-Montaña, J., J. K. Zimmerman, and J. Thompson. 2010. Population structure, growth rates and spatial distribution of two dioecious tree species in a wet forest in Puerto Rico. Iournal of Tropical Ecology 26:433-443.

Freeman, D. C., J. L. Doust, A. El-Keblawy, K. J. Miglia, and E. D. McArthur. 1997. Sexual specialization and inbreeding avoidance in the evolution of dioecy. Botanical Review 63:65-92.

Grueber, C. E., S. Nakagawa, R. J. Laws, and I. G. Jamieson. 2011. Multimodel inference in ecology and evolution: challenges and solutions. Journal of Evolutionary Biology 24:699-711.

Haridas, C. V., E. A. Eager, R. Rebarber, and B. Tenhumberg. 2014. Frequency-dependent population dynamics: effect of sex ratio and mating system on the elasticity of population growth rate. Theoretical Population Biology 97:49-56.

Harms, K. E., S. J. Wright, O. Calderón, A. Hernández, and E. A. Herre. 2000. Pervasive density-dependent recruitment enhances seedling diversity in a tropical forest. Nature 404:493-495.

Heilbuth, J. C., K. L. Ilves, and S. P. Otto. 2001. The consequences of dioecy for seed dispersal: modeling the seed-shadow handicap. Evolution 55:880-888.

Hubbell, S. P., and R. B. Foster. 1983. Diversity of canopy trees in a Neotropical forest and implications for conservation. Special Publications Series of the British Ecological Society.

- 1992. Short-term dynamics of a Neotropical forest: why ecological research matters to tropical conservation and management. Oikos 63:48-61.

Kraft, N. J. B., M. R. Metz, R. S. Condit, and J. Chave. 2010. The relationship between wood density and mortality in a global tropical forest data set. New Phytologist 188:1124-1136.

Lebrija-Trejos, E., S. J. Wright, A. Hernández, and P. B. Reich. 2014. Does relatedness matter? phylogenetic density-dependent survival of seedlings in a tropical forest. Ecology 95:940-951.
Leigh, E. G. 1999. Tropical forest ecology: a view from Barro Colorado Island. Oxford University Press, Oxford.

Melampy, M. N., and H. F. Howe. 1977. Sex ratio in the tropical tree Triplaris americana (Polygonaceae). Evolution 31:867-872.

Metcalf, C. J. E., and S. Pavard. 2007. Why evolutionary biologists should be demographers. Trends in Ecology and Evolution 22:205-212.

Moles, A. T., D. S. Falster, M. R. Leishman, and M. Westoby. 2004. Small-seeded species produce more seeds per square metre of canopy per year, but not per individual per lifetime. Journal of Ecology 92:384-396.

Moles, A. T., and M. Westoby. 2006. Seed size and plant strategy across the whole life cycle. Oikos 113:91-105.

Muller-Landau, H. C. 2004. Interspecific and inter-site variation in wood specific gravity of tropical trees. Biotropica 36:20-32.

Muller-Landau, H. C., S. J. Wright, O. Calderón, R. Condit, and S. P. Hubbell. 2008. Interspecific variation in primary seed dispersal in a tropical forest. Iournal of Ecology 96:653-667.

Opler, P. A., and K. S. Bawa. 1978. Sex ratios in tropical forest trees. Evolution 32:812-821.

Ortiz-Pulido, R., and N. P. Pavon. 2010. Influence of slope orientation on sex ratio and size distribution in a dioecious plant Bursera fagaroides var. purpusii (Brandeg.) McVaugh and Rzed. (Burseraceae). Plant Ecology 208:271-277.

Poorter, L., S. J. Wright, H. Paz, D. D. Ackerly, R. Condit, G. IbarraManríquez, K. E. Harms, et al. 2008. Are functional traits good predictors of demographic rates? evidence from five Neotropical forests. Ecology 89:1908-1920.

Puerta-Piñero, C., H. C. Muller-Landau, O. Calderón, and S. J. Wright 2013. Seed arrival in tropical forest tree fall gaps. Ecology 94:15521562.

Queenborough, S. A., D. F. R. P. Burslem, N. C. Garwood, and R. Valencia. 2007. Determinants of biased sex ratios and inter-sex costs of reproduction in dioecious tropical forest trees. American Journal of Botany 94:67-78.

Queenborough, S. A., S. J. Mazer, S. M. Vamosi, N. C. Garwood, R. Valencia, and R. Freckleton. 2009. Seed mass, abundance and breeding system among tropical forest species: do dioecious species exhibit compensatory reproduction or abundances? Lournal of Ecology 97:555-566.

$\mathrm{R}$ Core Team. 2016. R: a language and environment for statistical computing. R Foundation for Statistical Computing, Vienna.

Renner, S. S., and R. E. Ricklefs. 1995. Dioecy and its correlates in the flowering plants. American Journal of Botany 82:596-606.

Spigler, R. B., and T.-L. Ashman. 2012. Gynodioecy to dioecy: are we there yet? Annuals of Botany 109:531-543.

Vamosi, J. C., Y. Zhang, and W. G. Wilson. 2007. Animal dispersal dynamics promoting dioecy over hermaphroditism. American Naturalist 170:485-491.

Vamosi, S. M., S. J. Mazer, and F. Cornejo. 2008. Breeding systems and seed size in a Neotropical flora: testing evolutionary hypotheses. Ecology 89:2461-2472.

Vamosi, S. M., and S. A. Queenborough. 2010. Breeding systems and phylogenetic diversity of seed plants along a large-scale elevational gradient. Journal of Biogeography 37:465-476.

Visser, M. D., M. Bruijning, S. J. Wright, H. C. Muller-Landau, E. Jongejans, L. S. Comita, and H. de Kroon. 2016a. Functional traits as predictors of vital rates across the life-cycle of tropical trees. Functional Ecology 30:168-180.

- 2016b. Data from: Functional traits as predictors of vital rates across the life cycle of tropical trees. Functional Ecology 30:168- 
180, Dryad Digital Repository, http://dx.doi.org/10.5061/dryad .fm654.

Visser, M. D., E. Jongejans, M. van Breugel, P. A. Zuidema, Y.-Y. Chen, A. R. Kassim, and H. de Kroon. 2011. Strict mast fruiting for a tropical dipterocarp tree: a demographic cost-benefit analysis of delayed reproduction and seed predation. Iournal of Ecology 99:1033-1044.

Whittingham, M. J., P. A. Stephens, R. B. Bradbury, and R. P. Freckleton. 2006. Why do we still use stepwise modelling in ecology and behaviour? Journal of Animal Ecology 75:1182-1189.

Williams, J. L., T. E. X. Miller, and S. P. Ellner. 2012. Avoiding unintentional eviction from integral projection models. Ecology 93 2008-2014.

Wright, S. J., M. Bruijning, D. Brassfield, A. Cerezo, and M. D. Visser. 2015a. The Barro Colorado Island tree reproduction dataset. Smithsonian DSpace Repository, http://dx.doi.org/10.5479/si.data .201511251100

Wright, S. J., and O. Calderón. 2016. Seed data per trap for 18 Barro Colorado Island tree species for the period 2008-2012. Smithsonian DSpace Repository, https://dx.doi.org/10.5479/10088/29572.

Wright, S. J., O. Calderón, and A. Hernández. 2015b. Estimates of mean seed-to-seedling transition probabilities for 68 Barro Colorado Island tree species for the period 1993-2012. Smithsonian DSpace Repository, http://dx.doi.org/10.5479/si.data.201511 251134.

Wright, S. J., and A. Hernández. 2016. Heights of new recruits for 69 Barro Colorado Island tree species for the period 1995-2011. Smithsonian DSpace Repository, http://dx.doi.org/10.5479/10088/29573.
Wright, S. J., M. A. Jaramillo, J. Pavon, R. Condit, S. P. Hubbell, and R. B. Foster. 2005a. Reproductive size thresholds in tropical trees: variation among individuals, species and forests. Journal of Tropical Ecology 21:307-315.

Wright, S. J., K. Kitajima, N. J. B. Kraft, P. B. Reich, I. J. Wright, D. E. Bunker, R. Condit, et al. 2010. Functional traits and the growthmortality trade-off in tropical trees. Ecology 91:3664-3674.

Wright, S. J., H. C. Muller-Landau, O. Calderón, and A. Hernandéz. 2005b. Annual and spatial variation in seedfall and seedling recruitment in a Neotropical forest. Ecology 86:848-860.

Zapata, T. R., and M. T. K. Arroyo. 1978. Plant reproductive ecology of a secondary deciduous tropical forest in Venezuela. Biotropica 10:221-230.

\section{References Cited Only in the Online Appendixes}

Clark, J. S., M. Silman, R. Kern, E. Macklin, and J. HilleRisLambers. 1999. Seed dispersal near and far: patterns across temperate and tropical forests. Ecology 80:1475-1494.

Ribbens, E., J. A. Silander, and S. W. Pacala. 1994. Seedling recruitment in forests: calibrating models to predict patterns of tree seedling dispersion. Ecology 75:1794-1806.

Associate Editor: Michael G. Neubert Editor: Alice A. Winn 